\title{
Blast-Induced Damage on Millisecond Blasting Model Test with Multicircle Vertical Blastholes
}

\author{
Qin-yong Ma, Pu Yuan, Jing-shuang Zhang, Rui-qiu Ma, and Bo Han \\ Research Center of Mine Underground Engineering, Ministry of Education, Anhui University of Science and Technology, \\ Huainan, Anhui 232001, China
}

Correspondence should be addressed to Pu Yuan; puy2012@126.com

Received 12 November 2014; Accepted 26 January 2015

Academic Editor: Marcin A. Lutynski

Copyright (C) 2015 Qin-yong Ma et al. This is an open access article distributed under the Creative Commons Attribution License, which permits unrestricted use, distribution, and reproduction in any medium, provided the original work is properly cited.

\begin{abstract}
To investigate the blast-induced damage effect on surrounding rock in vertical shaft excavation, 4 kinds of millisecond blasting model tests with three-circle blastholes were designed and carried out with excavation blasting in vertical shaft as the background. The longitudinal wave velocity on the side of concrete model was also measured before and after blasting. Then blast damage factor was then calculated by measuring longitudinal wave velocity before and after blasting. The test results show that the blastinduced damage factor attenuated gradually with the centre of three-circle blastholes as centre. With the threshold value of 0.19 for blast-induced damage factor, blast-induced damage zones for 4 kinds of model tests are described and there is an inverted cone blast-induced damage zone in concrete model. And analyses of cutting effect and blast-induced damage zone indicate that in order to minimize the blast-induced damage effect and ensure the cutting effect the reasonable blasting scheme for three-circle blastholes is the inner two-circle blastholes initiated simultaneously and the outer third circle blastholes initiated in a $25 \mathrm{~ms}$ delay.
\end{abstract}

\section{Introduction}

In recent decades, drilling blasting technology has been widely used in mining engineering, tunneling engineering, large slope engineering, underground engineering, and other kinds of rock engineering [1]. Only part of explosive energy is used to crush rocks to achieve the goal of rock mass excavation, while most of the energy is transferred into surrounding rock mass as heat, vibration, and air shock wave to make surrounding rock mass or structure damaged or even destroyed at the same time [2,3]. Rock blasting damage affects the security, support, and reinforcement cost of underground engineering directly or indirectly.

The mechanical properties of blasting damaged rock and the regularities of rock damage by blasting have been investigated in various distances and blasting conditions with marble, and both spreading regularities of mesocrack and damaged properties of blasting damaged rock have also been analyzed by elastic-brittle mesodamage model [3]. The excavation damage zones of Renhechang tunnel resulting from blasting have been studied by an ultrasonic wave measurement, and blasting effect for two types of detonators, nonel detonator and electronic detonator, have been compared. As the delay time of electronic detonator can be arbitrarily set up, the use of electronic detonator can lead to not only a small extent of excavation damage zones, but also a lower degree of rock breakage in excavation damage zones [4]. A new model for predicting the extent of blast-induced damage in rock mass has been proposed based on Langefors' theory of rock blasting [5]. The excavation damage of a granite tunnel resulting from blasting has been characterized by carrying out ultrasonic wave velocity and amplitude measurements around one quadrant of the test tunnel [6]. Blast design wants to cause minimum damage and overbreak with respect to existing in situ stress filed and support system; then the controlling parameters for blastinduced damage and overbreak have been investigated [7]. The cumulative effect of blast-induced damage and damage evolutive law of rock mass have been researched by carrying out sound wave measurement for surrounding rock after blasting repeatedly; then a cumulative expanded model for predicting blast-induced damage has been put forward with the baseline of rock mass wave velocity reducing ratio $[2,8]$. According to the similarity theory, blasting-induced damage 
TABLE 1: Charging scheme.

\begin{tabular}{lcccc}
\hline Model number & CM-1 & CM-2 & CM-3 & CM-4 \\
Detonation delay & $25 \mathrm{~ms}$ & $50 \mathrm{~ms}$ & $25 \mathrm{~ms}$ & $50 \mathrm{~ms}$ \\
First circle & Electric detonator segment & Electric detonator segment & Electric detonator segment & Electric detonator segment \\
& I & I & I & I \\
Second circle & Electric detonator segment & Electric detonator segment & Electric detonator segment & Electric detonator segment \\
Third circle & Electric detonator segment & Electric detonator segment & Electric detonator segment & Electric detonator segment \\
& II & V & III & V \\
\hline
\end{tabular}

model test is conducted in simulated coal, and both ultrasonic wave velocity and blasting strain waves have been measured. The results indicate that the simulated coal damage is the results of the interaction of blasting shock wave, blasting stress wave, detonation gas, and coal gas $[9,10]$.

Excavation and surrounding rock protection are always a contradiction problem in blasting engineering. In order to investigate the blast-induced damage effect on surrounding rock in vertical shaft excavation, 4 kinds of millisecond blasting model tests with three-circle blastholes have been implemented, and the blast-induced damage of millisecond blasting to surrounding rock has also been investigated by ultrasonic wave velocity measurement. Then a reasonable blasting parameter for engineering blasting design and in situ blasting engineering construction has been put forward.

\section{Design of Millisecond Blasting Model Test}

In order to investigate the blast-induced damage on surrounding rock in vertical shaft excavation, 4 kinds of millisecond blasting model tests with three-circle blastholes in concrete model have been designed with parallel cut blasting in vertical shaft as prototype.

P.O 42.5 ordinary Portland cement was adopted to prepare the concrete specimen. The fine aggregate used in this study was natural river sand with a fineness modulus of 2.6, a silt content of $2.0 \%$. The coarse aggregate used was gravel with continuous grading from $16 \mathrm{~mm}$ to $31.5 \mathrm{~mm}$, a silt content of $0.6 \%$. Moreover, HNT-K3 concrete waterproofing agent was mixed. The mix proportion of cement, water, sand, gravel, and admixture in concrete is 1.00, 0.43, 1.49, 2.89 , and 0.08 , respectively. The length of concrete model is $1000 \mathrm{~mm}$, the width is $1000 \mathrm{~mm}$, and the height is $600 \mathrm{~mm}$. The basic mechanical test after curing $28 \mathrm{~d}$ shows that the cubic compressive strength of model concrete is $42.8 \mathrm{MPa}$, and its splitting tensile strength is $2.58 \mathrm{MPa}$. Ultrasonic wave velocity measurement indicates that the longitudinal wave velocity of model concrete is $4209 \mathrm{~m} / \mathrm{s}$ [11].

Three-circle blastholes are arranged in the middle of concrete model. The diameter of first circle is $60 \mathrm{~mm}$, and there are 4 blastholes in the first circle with a space of $43 \mathrm{~mm}$. The diameter of second circle is $120 \mathrm{~mm}$, and there are 6 blastholes in the second circle with a space of $60 \mathrm{~mm}$. The diameter of third circle is $200 \mathrm{~mm}$, and there are 10 blastholes in the third circle with a space of $62 \mathrm{~mm}$. The depth of blastholes in the first circle and second circle is $180 \mathrm{~mm}$, while the depth of blastholes in the third circle is $160 \mathrm{~mm}$. Blastholes

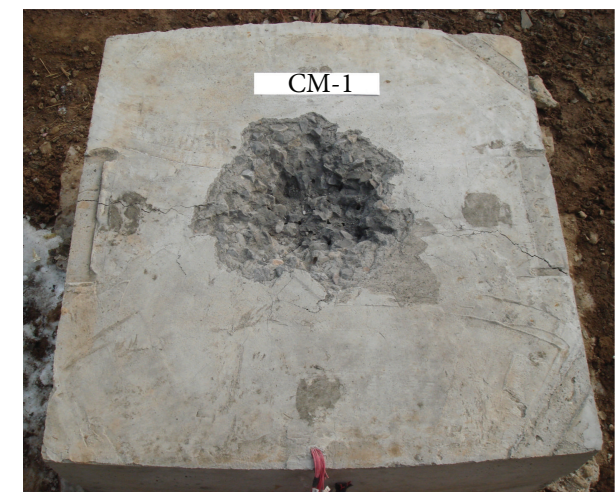

Figure 1: Blasting effect of concrete model with three-circle blastholes.

are formed by pulling out embedded circular steel bar after initial setting and before final setting. Each blasthole charges with one number 6 millisecond delay electric detonatar. The 4 kinds of millisecond blasting model tests are named CM-1, CM-2, CM-3, and CM-4. The charging scheme for millisecond blasting model tests is shown in Table 1.

\section{Blasting Effect in Concrete Model}

After blasting, the cutting effect in concrete model is shown in Figure 1. Then the blasting cavity is cleaned and blasting fragments are gathered. The cutting depth is measured by ruler and its value is the mean of 4 measured depths. Delimiting the boundary of blasting cavity, the cavity radius is the mean of longest radius and shortest radius. After measuring cutting depth and cavity radius, put a plastic film on blasting cavity and fill blasting cavity with dry fine sand. The cutting volume of blasting cavity can be calculated by measuring the volume of dry sand in blasting cavity. The cutting depth, cavity radius, and cutting volume of 4 kinds of millisecond blasting model tests are shown in Table 2.

\section{Blast-Induced Damage Measurement}

4.1. Indicator for Blast-Induced Damage. The break and damage of rock mass resulting from blasting can be reflected by the deterioration of mechanical properties and initiation and development of inner crack. At present, damage variable is adopted to describe the blast-induced damage and the evolutive law of blast-induced damage. And damage variable 
TABLE 2: Blasting effect of millisecond blasting model test.

\begin{tabular}{lccc}
\hline $\begin{array}{l}\text { Model } \\
\text { number }\end{array}$ & $\begin{array}{c}\text { Cutting depth/ } \\
\mathrm{mm}\end{array}$ & $\begin{array}{c}\text { Cavity radius/ } \\
\mathrm{mm}\end{array}$ & $\begin{array}{c}\text { Cutting volume/ } \\
\mathrm{cm}^{3}\end{array}$ \\
\hline CM-1 & 64 & 260 & 3010 \\
CM-2 & 57 & 290 & 2805 \\
CM-3 & 49 & 369 & 4975 \\
CM-4 & 118 & 427 & 10705 \\
\hline
\end{tabular}

can be evaluated by damage area, density change, elastic modulus change, longitudinal wave velocity change, and CT value change before and after blasting $[10,12]$. Since the longitudinal wave velocity is very sensitive about the joints and cracks in rock mass or concrete specimens, rock or concrete damage characteristics can be well described by longitudinal wave velocity change. And ultrasonic detection is a simple, undamaged, practicable, and widely used method for rock or concrete damage evaluation.

After comprehensive comparison, longitudinal wave velocity change before and after blasting is selected to evaluate the blast-induced damage in concrete model [12-14]. The blast-induced damage factor $D$ can be calculated by the following equation:

$$
D=1-\left(\frac{v}{v_{0}}\right)^{2}=1-\eta^{2}
$$

where $v_{0}$ and $v$ are the longitudinal wave velocity of concrete model before and after blasting, and its unit is $\mathrm{m} / \mathrm{s} . \eta$ is the reduction rate of longitudinal wave velocity after blasting.

4.2. Arrangement of Measuring Points. To investigate the blast-induced damage effect on the model concrete, measuring points for longitudinal wave velocity test are arranged with horizontal and vertical lines at the center of the concrete model profile as the baselines. There are 36 measuring points in 4 lines and 9 rows with a space of $100 \mathrm{~mm}$. The distance from the measuring points in the first line to the upper surface of concrete model is $150 \mathrm{~mm}$ which is a little higher than the charging center. The measuring points on concrete model can be seen in Figure 2.

The longitudinal wave velocity of concrete model is measured by NM-4A nonmetal ultrasonic detecting instrument. When measuring the longitudinal wave velocity of concrete model before and after blasting tests, the transmitter probe and receiver probe should be clingy on the concrete surface at measuring points with vaseline as couplant. During the test, the center of probe should be at the same position with the measuring points. The longitudinal wave velocity measurement is conducted in turn from top to bottom, from left to right. The value in stable waveform is the test result.

4.3. Measuring Results of Blast-Induced Damage. After analyzing the measuring results of longitudinal wave velocity of concrete model before and after blasting tests, the blastinduced damage factors for 4 kinds of concrete models are obtained, which can be seen in Table 3 .

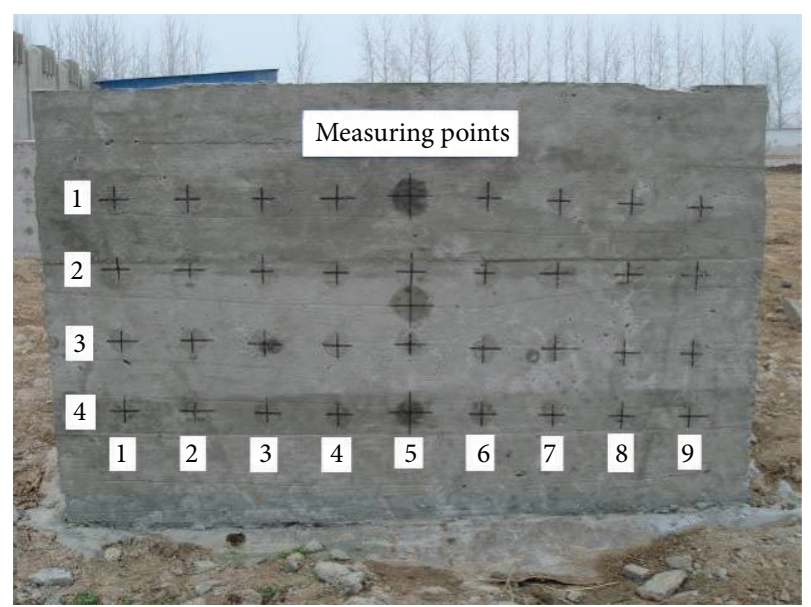

FIGURE 2: Measuring points of longitudinal wave velocity on concrete model.

According to the blast-induced damage results of millisecond blasting model test, the change curve of blastinduced damage factor in concrete model is drawn in Figure 3.

In CM-1, CM-2, and CM-3, the change trends of blastinduced damage factor in the first line and second line of CM1 and the first line of CM-2 are obviously different from other lines. But both the peak value of blast-induced damage factor in the first line and second line of CM-1 and the peak value of blast-induced damage factor in the first line of CM-2 appear in the first row. The peak value of blast-induced damage factor in most of lines in CM-1, CM-2, and CM-3 appears in the fifth row which is the middle of concrete model. The singular change trend in CM-1 and CM-2 is the result of the blast-induced crack crossing the measuring points. The blastinduced damage factor attenuates with the center of threecircle blastholes as center.

In CM-4, the concrete model has been broken and some large cracks have been extended to the model boundary. Thus the blast-induced damage factor is much bigger than other concrete models. And the change trend of blast-induced damage factor has been changed because of those large cracks.

\section{Analyses of Blast-Induced Damage}

When the reduction rate of longitudinal wave velocity after blasting exceeds $10 \%$, the rock mass can be regarded as damage and the critical blast-induced damage factor is 0.19 [12]. Then the threshold blast-induced damage factor, 0.19 , is adopted to define the blast-induced damage zone. The blastinduced damage in CM-1 and CM-2 is mainly on the left side of concrete model. The depth of blast-induced damage for CM-1 is about $280 \mathrm{~mm}$, seen in Figure 4(a). The depth of blast-induced damage for CM-2 is about $321 \mathrm{~mm}$, and the blast-induced damage zone has extended to the left boundary of concrete model and extended to the right about $140 \mathrm{~mm}$, as seen in Figure 4(b). The depth of blast-induced damage for CM-3 is about $273 \mathrm{~mm}$, and the blast-induced damage zone 
TABLE 3: Blast-induced damage factor in concrete model with three-circle blastholes.

\begin{tabular}{|c|c|c|c|c|c|c|c|c|c|c|}
\hline \multirow{2}{*}{ Model number } & \multirow{2}{*}{ Line } & \multicolumn{9}{|c|}{ Row } \\
\hline & & 1 & 2 & 3 & 4 & 5 & 6 & 7 & 8 & 9 \\
\hline \multirow{4}{*}{ CM-1 } & 1 & 0.692 & 0.109 & 0.110 & 0.075 & 0.110 & 0.072 & 0.077 & 0.084 & 0.087 \\
\hline & 2 & 0.300 & 0.047 & 0.345 & 0.126 & 0.137 & 0.082 & 0.058 & 0.031 & 0.014 \\
\hline & 3 & 0.041 & 0.083 & 0.060 & 0.072 & 0.066 & 0.067 & 0.044 & 0.044 & 0.051 \\
\hline & 4 & 0.018 & 0.004 & 0.010 & 0.021 & 0.047 & 0.031 & 0.027 & 0.031 & 0.034 \\
\hline \multirow{4}{*}{ CM-2 } & 1 & 0.707 & 0.423 & 0.405 & 0.257 & 0.330 & 0.231 & 0.111 & 0.063 & 0.086 \\
\hline & 2 & 0.075 & 0.099 & 0.108 & 0.135 & 0.290 & 0.180 & 0.100 & 0.066 & 0.017 \\
\hline & 3 & 0.073 & 0.082 & 0.078 & 0.094 & 0.150 & 0.106 & 0.069 & 0.035 & 0.000 \\
\hline & 4 & 0.023 & 0.032 & 0.059 & 0.042 & 0.112 & 0.062 & 0.022 & 0.032 & 0.000 \\
\hline \multirow{4}{*}{ CM-3 } & 1 & 0.067 & 0.078 & 0.095 & 0.195 & 0.503 & 0.493 & 0.470 & 0.236 & 0.170 \\
\hline & 2 & 0.010 & 0.024 & 0.056 & 0.091 & 0.202 & 0.179 & 0.107 & 0.064 & 0.115 \\
\hline & 3 & 0.000 & 0.000 & 0.037 & 0.064 & 0.105 & 0.094 & 0.069 & 0.051 & 0.071 \\
\hline & 4 & 0.007 & 0.000 & 0.030 & 0.036 & 0.072 & 0.121 & 0.054 & 0.057 & 0.054 \\
\hline \multirow{4}{*}{ CM-4 } & 1 & 0.774 & 0.809 & 0.793 & 0.878 & 0.917 & 0.876 & 0.870 & 0.846 & 0.806 \\
\hline & 2 & 0.772 & 0.773 & 0.695 & 0.796 & 0.792 & 0.790 & 0.833 & 0.760 & 0.633 \\
\hline & 3 & 0.609 & 0.659 & 0.673 & 0.802 & 0.811 & 0.512 & 0.698 & 0.865 & 0.539 \\
\hline & 4 & 0.595 & 0.692 & 0.748 & 0.750 & 0.687 & 0.657 & 0.844 & 0.770 & 0.743 \\
\hline
\end{tabular}

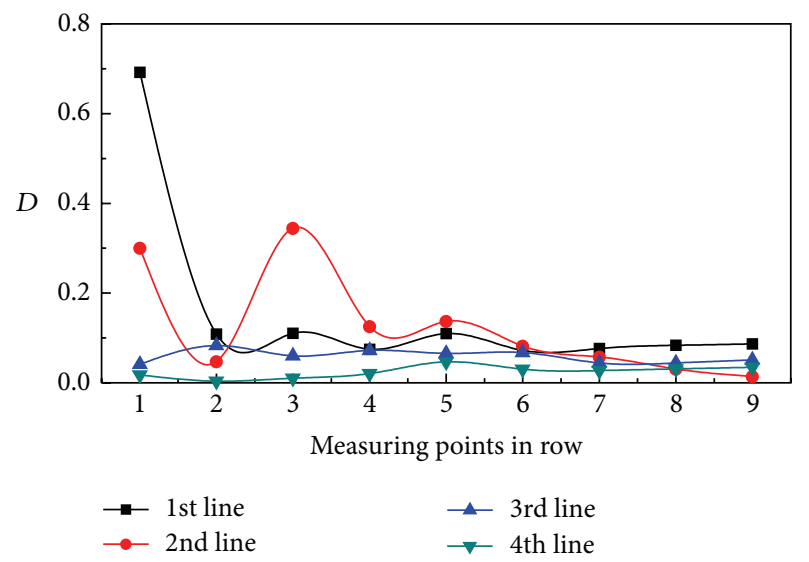

(a) $\mathrm{CM}-1$

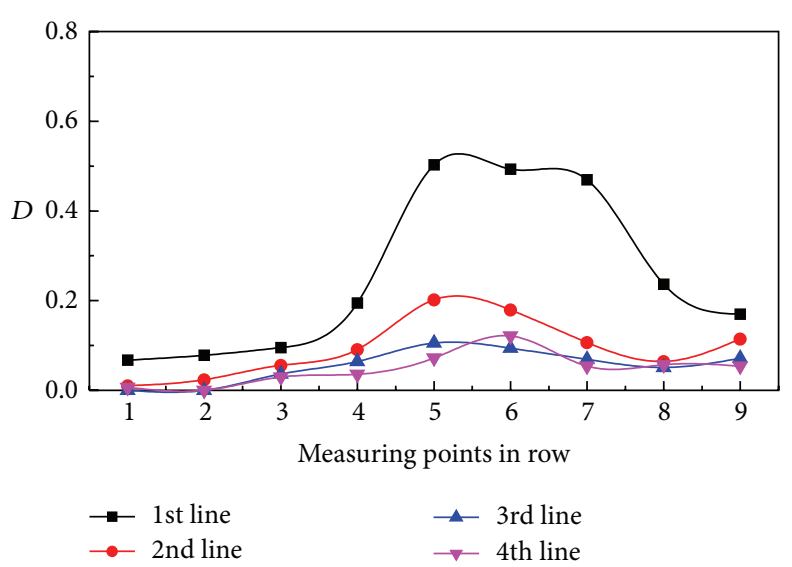

(c) $\mathrm{CM}-3$

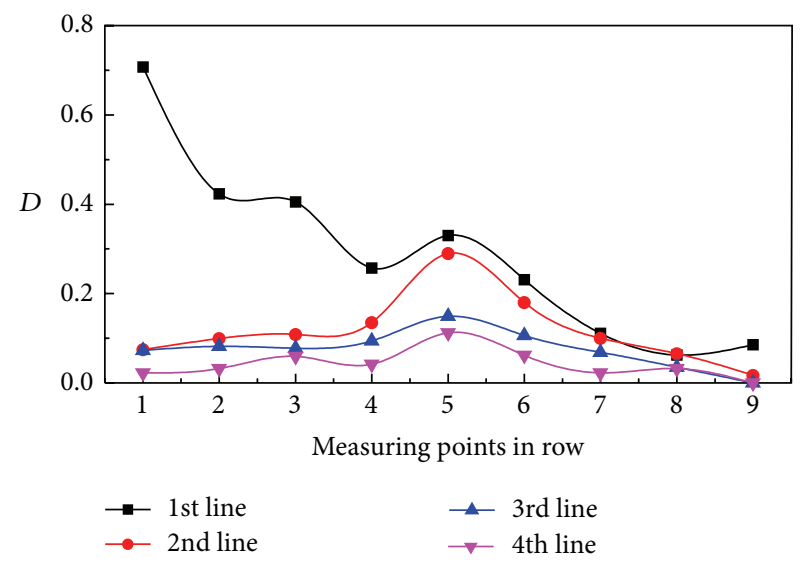

(b) $\mathrm{CM}-2$

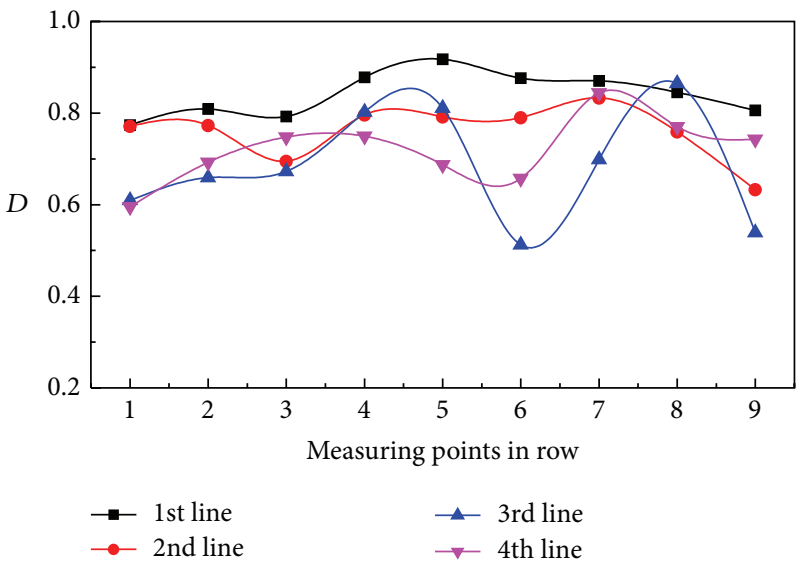

(d) $\mathrm{CM}-4$

Figure 3: Curve of blast-induced damage factor $D$. 


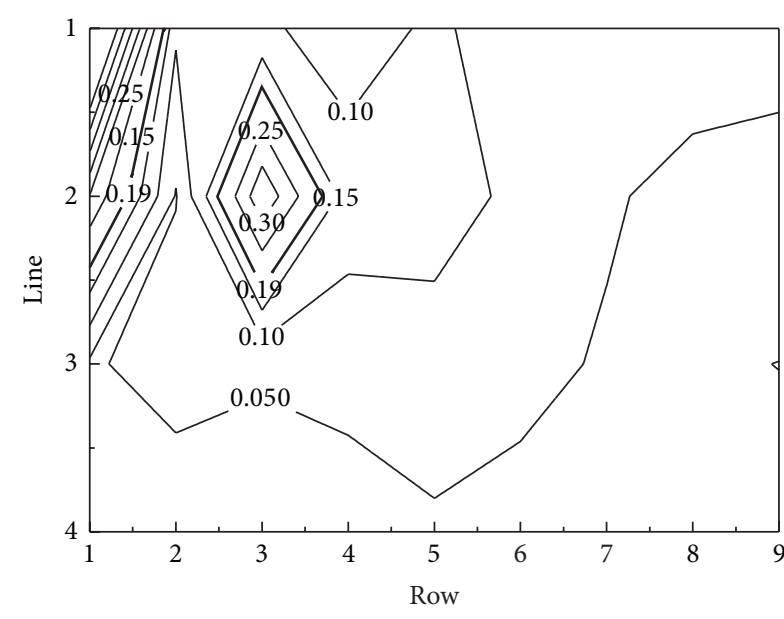

(a) $\mathrm{CM}-1$

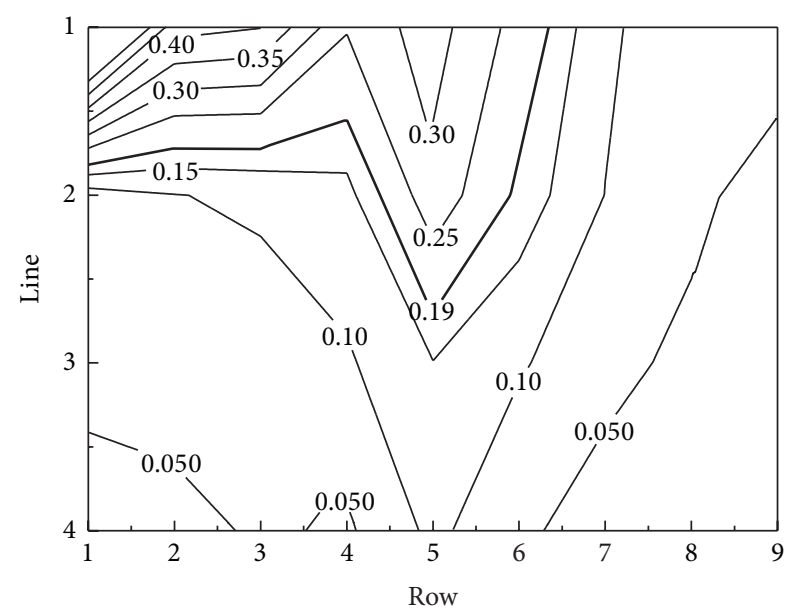

(b) $\mathrm{CM}-2$

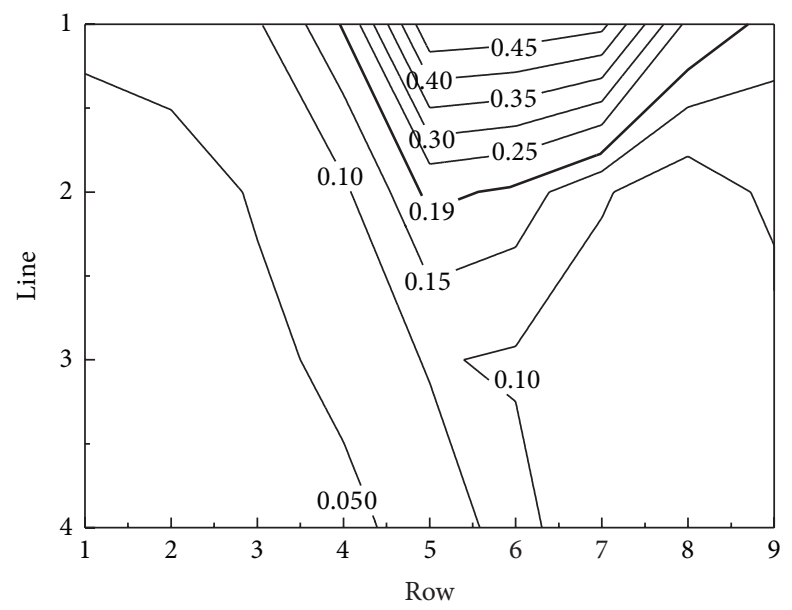

(c) $\mathrm{CM}-3$

FIgURE 4: Blast-induced damage zone in model.

has extended to the left about $103 \mathrm{~mm}$ and to the right about $370 \mathrm{~mm}$, as seen in Figure 4(c). For many cracks in CM-4, the blast-induced damage factor is much big and the smallest blast-induced damage factor is 0.512 . So the whole concrete model in CM-4 is in blast-induced damage zone. The blastinduced damage zone is in an inverted cone distribution with the center line of three-circle blastholes as center line, as seen in Figure 4. The bold line in Figure 4 corresponds to the threshold value of blast-induced damage factor, 0.19.

It is considered that the left side of concrete model which has not been vibrated compactly for its longitudinal wave velocity is a little smaller than the right side. So the blastinduced damage zone in CM-1 is mainly on the left side of concrete model not in the blastholes area. And the blastinduced damage zone in CM-2 is mainly on blasthole areas and left side of concrete model, and the depth in blastholes areas is bigger than that in left side.

Comparing CM-1 with CM-2, the blast-induced damage factor in CM-2 is much bigger than that in CM-1, and its depth is about 1.15 times bigger than that for CM-1. And the cutting depth and cutting volume for CM-1 are better than that in CM-2, and its cavity radius is smaller than that in CM2, which means a light overbreak.

The blast-induced damage zone in CM-3 is mainly on the blastholes areas and right side of concrete model, in an inverted coned distribution. For the large blast-induced damage factor, the whole concrete model in CM-4 is in blast-induced damage zone. The cavity radius of CM-4 is $427 \mathrm{~mm}$ which is much bigger than the radius of the third circle blastholes, causing a heavy overbreak and damage to surrounding rock. Comparing CM-3 with CM-4, the cutting depth, cutting volume, and cavity radius of CM-4 are much bigger than that of CM-3, but its blast-induced damage effect is too large and a serious influence of surrounding rock stability presents. So the blasting parameters in CM- 4 are not suggested to be adopted.

CM-3 shows that the cutting volume is big, and the cutting depth is small, which means an overbreak in CM-

3. Comparing CM-1 and CM-3, the blast-induced damage factor for CM-1 is much smaller than that in CM-3.

After comprehensive consideration of the blast-induced damaged factor, blast-induced damage zone distribution, and 
cutting effect in 4 kinds of millisecond blasting model tests, it is thought that the CM-1 presents not only a smaller blast-induced damage factor and blast-induced damage zone distribution but also a bigger cutting depth and smaller cavity radius. So in order to minimize the blast-induced damage effect on surrounding rock under the condition of good cutting effect, the reasonable blasting scheme for threecircle blastholes is the inner two-circle blastholes initiated simultaneously and the outer third circle blastholes initiated in a $25 \mathrm{~ms}$ delay.

\section{Conclusions}

(1) The measured longitudinal wave velocity on the side of concrete model before and after blasting indicates that the blast-induced damage factor attenuates gradually with the centre of three-circle blastholes as centre.

(2) With the threshold value of 0.19 for blast-induced damage factor, blast-induced damage zone for 4 kinds of model tests is in an inverted cone distribution with the center line of three-circle blastholes as center line.

(3) In order to minimize the blast-induced damage effect on surrounding rock under the condition of good cutting effect, the reasonable blasting scheme for threecircle blastholes is the inner two-circle blastholes initiated simultaneously and the outer third circle blastholes initiated in a $25 \mathrm{~ms}$ delay.

\section{Conflict of Interests}

The authors declare that there is no conflict of interests regarding the publication of this paper.

\section{References}

[1] B. Han, Model Experimental Study and Application of DeepHole Blasting in Hard Rock for Mine Shaft, Anhui University of Science and Technology, 2013 (Chinese).

[2] C.-B. Yan, "Blasting damage cumulative effect of rock mass based on sound velocity variation," Rock and Soil Mechanics, vol. 31, supplement 1, pp. 187-192, 2010 (Chinese).

[3] X.-L. Yang, X.-Y. Yuan, Z. Wu, and C.-D. Su, "The experimental study on mechanical properties of blast damaged rock," Chinese Journal of Rock Mechanics and Engineering, vol. 20, no. 4, pp. 436-439, 2001 (Chinese).

[4] H.-X. Fu, L. N. Y. Wong, Y. Zhao, Z. Shen, C.-P. Zhang, and Y.-Z. Li, "Comparison of excavation damage zones resulting from blasting with nonel detonators and blasting with electronic detonators," Rock Mechanics and Rock Engineering, vol. 47, no. 2, pp. 809-816, 2014.

[5] F. García Bastante, L. Alejano, and J. González-Cao, "Predicting the extent of blast-induced damage in rock masses," International Journal of Rock Mechanics and Mining Sciences, vol. 56, pp. 44-53, 2012.

[6] I. L. Meglis, T. Chow, C. D. Martin, and R. P. Young, "Assessing in situ microcrack damage using ultrasonic velocity tomography," International Journal of Rock Mechanics and Mining Sciences, vol. 42, no. 1, pp. 25-34, 2005.
[7] S. K. Mandal, "Parameters controlling blast-induced damage and overbreak," Journal of Mines, Metals and Fuels, vol. 60, no. 1-2, pp. 6-16, 2012.

[8] C.-B. Yan, G.-Y. Xu, and F. Yang, "Measurement of sound waves to study cumulative damage effect on surrounding rock under blasting load," Chinese Journal of Geotechnical Engineering, vol. 29, no. 1, pp. 88-93, 2007 (Chinese).

[9] H.-B. Chu, X.-L. Yang, W.-M. Liang, and Y.-Q. Yu, "Simulation experimental study on the coal blast mechanism," Journal of the China Coal Society, vol. 36, no. 9, pp. 1451-1456, 2011 (Chinese).

[10] H.-B. Chu, X.-L. Yang, W.-M. Liang, Y.-Q. Yu, and L.-P. Wang, "Experimental study on the blast damage law of the simulated coal," Journal of Mining and Safety Engineering, vol. 28, no. 3, pp. 488-492, 2011 (Chinese).

[11] Q.-Y. Ma, P. Yuan, B. Han, J.-S. Zhang, and H.-X. Liu, "Dynamic strain wave analyses of parallel cut blasting model tests for vertical shaft," in Proceedings of the ISRM European Regional Symposium on Rock Engineering and Rock Mechanics: Structures in and on Rock Masses (EUROCK '14), pp. 1159-1164, Taylor \& Francis, London, UK, May 2014.

[12] W.-H. Zhu, F. Ming, and C.-Z. Song, "Fractal study of rock damage under blasting loading," Rock and Soil Mechanics, vol. 32, no. 10, pp. 3131-3135, 2011 (Chinese).

[13] C.-Y. Zhu and S.-C. Yu, "Study on the criterion of rockmass damage caused by blasting," Engineering Blasting, vol. 7, no. 1, pp. 12-16, 2001 (Chinese).

[14] J. Dai, Dynamic Behaviors and Blasting Theory of Rock, Metallurgical Industry Press, Beijing, China, 2nd edition, 2013, (Chinese). 

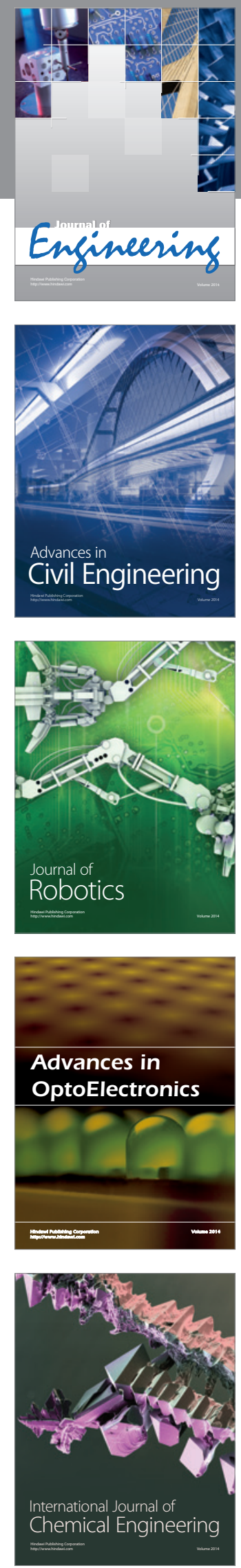

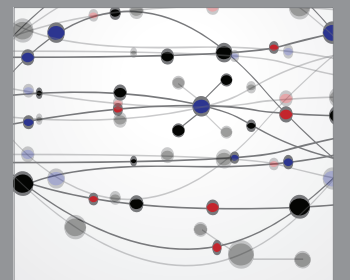

The Scientific World Journal
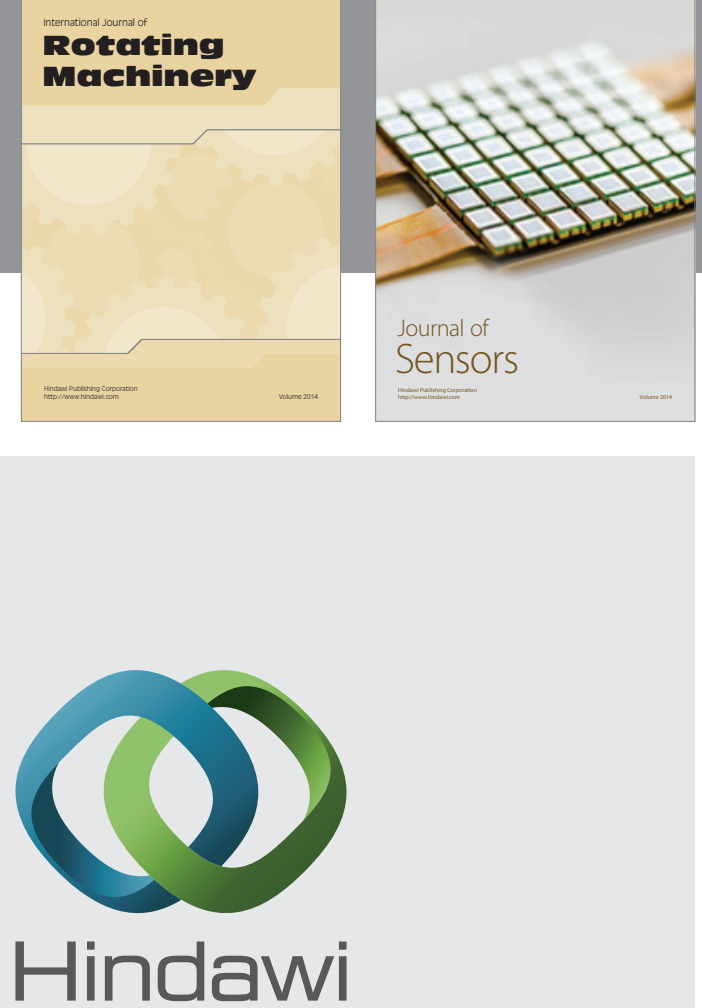

Submit your manuscripts at http://www.hindawi.com
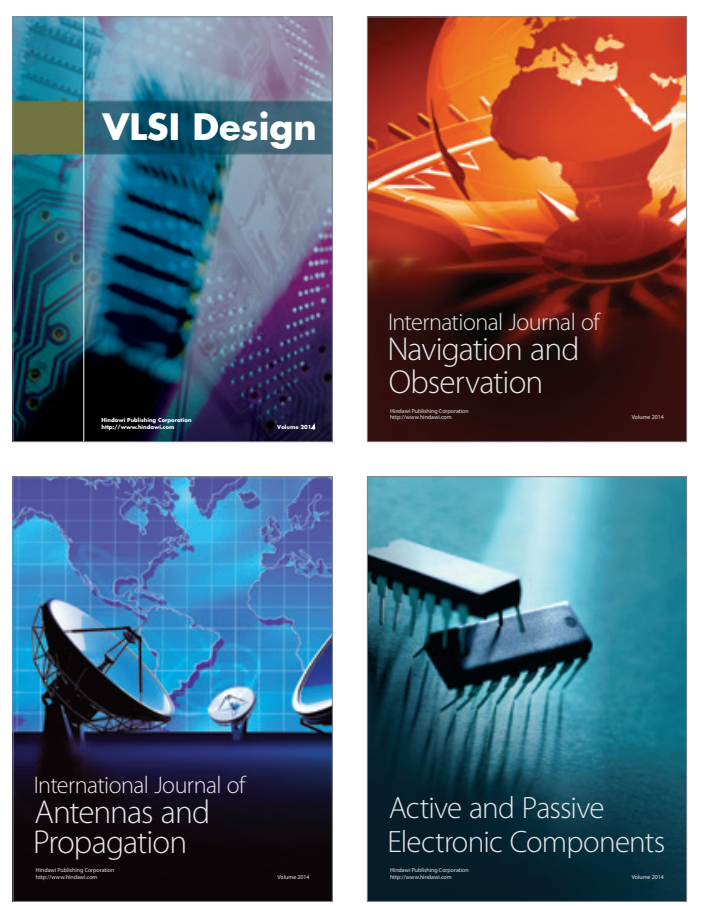
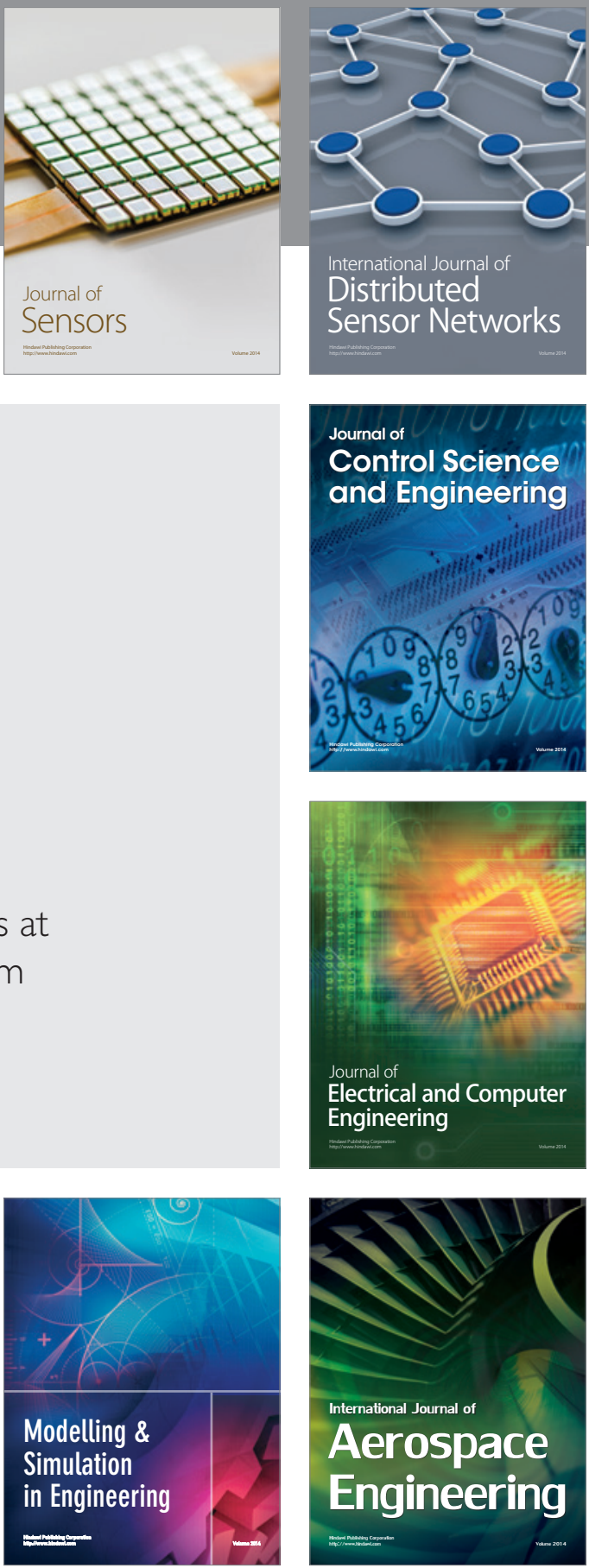

Journal of

Control Science

and Engineering
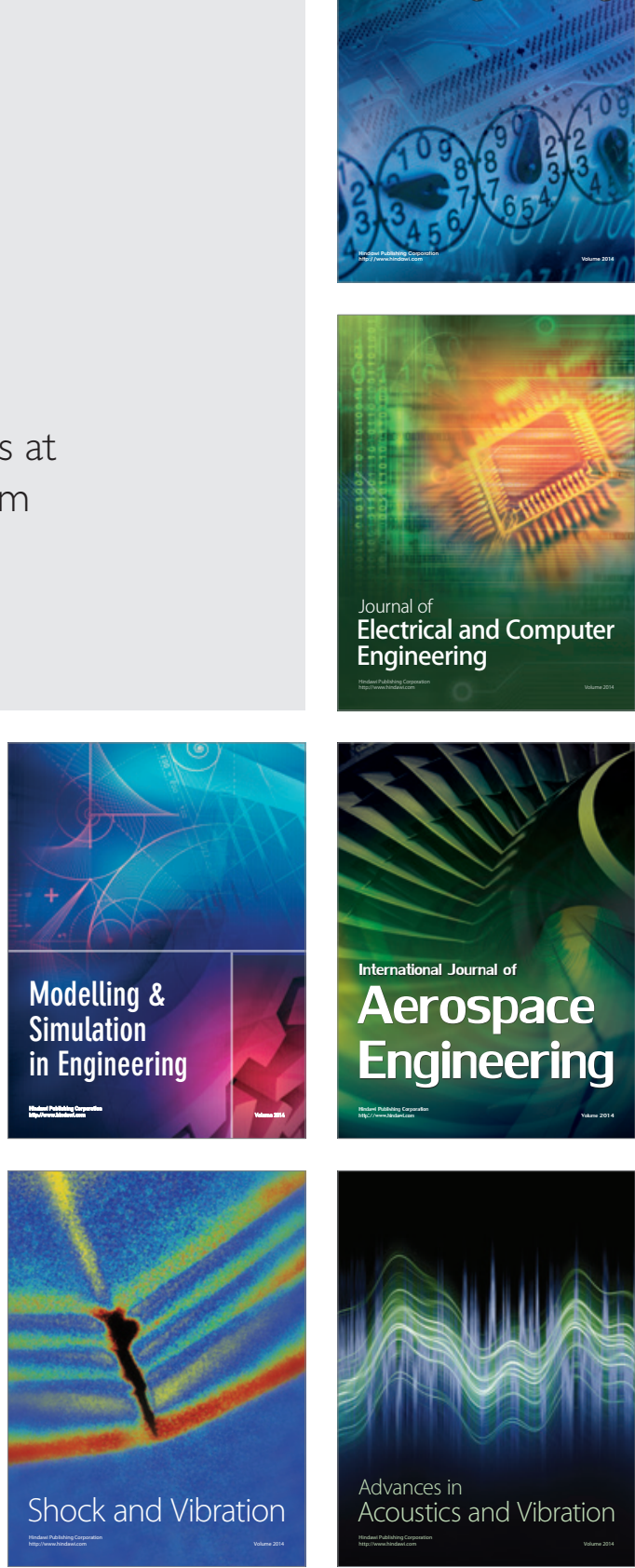